\title{
TCOM \\ Organizationally based citizen science: considerations for implementation
}

\section{Ashley A. Anderson, Elizabeth A. Williams, Marilee Long, Ellison Carter and John Volckens}

\begin{abstract}
This theoretical paper proposes a framework for how citizen science can be adapted to organizational contexts. Using an "input, process, output" approach, this model proposes organizational factors (e.g., communication channels and styles, and organizational structure) that should be considered when choosing among citizen science approaches (e.g., contributory, collaborative, co-created). The essay identifies possible outcomes for the individual, organization, and larger sector from employing a citizen science approach within an organizational setting.
\end{abstract}

Keywords

DOI
Citizen science; Health communication; Risk communication

https://doi.org/10.22323/2.19030201

Submitted: 25th October 2019

Accepted: 27th April 2020

Published: 18th May 2020
Increasingly, citizen science is recognized as an important approach for understanding public health problems [Rowbotham et al., 2019]. It enables non-traditional scientists to participate in developing research questions and responses to scientific problems, thus expanding the realm of who contributes to scientific knowledge production [Bonney et al., 2009]. It also allows scientists to conduct research on a larger scale thanks to the added resources citizen participants provide to collect, monitor, and classify large amounts of data. At the same time, citizen science projects must overcome key challenges to succeed. Scholars have emphasized identifying individuals' motivations to participate in projects and establishing ways to strengthen communication with volunteers in order to sustain their participation, and, thus, ensure a successful project.

While organizations have not traditionally been a setting for citizen science projects, we argue here they have clear potential for successful implementation of these projects and that by utilizing the organizational context, researchers can address the key problems of participation and communication that citizen science projects tend to face. The model proposed in this paper develops an organizational perspective for employing citizen science with a special emphasis on the components of communication to guide such work. Understanding an 
organization's culture, its members, and the communication flows that exist both within the organization and with external stakeholders is critical to the success of employing citizen science. Our model proposes ways that practitioners can approach organizationally based citizen science through understanding issues at the project outset (input), elements of a successful implementation (process), and potential consequences that follow project execution (output). The model suggests a suite of considerations for citizen science implementation within organizations. While organizations are often used in citizen science projects, the literature has not addressed the organizational framework as it relates to citizen science approaches.

We first review the literature on citizen science with an emphasis on two key challenges: motivations to participate and communication with citizen scientists. We then introduce the organization as a logical context for addressing these key challenges by describing an input-process-output model of organizationally based citizen science. We focus on the workplace as the organizational context, because occupational health and safety is a considerable enterprise that could benefit from greater involvement of workers [Moore et al., 2019]. Scholars are paying greater attention to the safety climate, including perceptions of and commitment to safety [Zohar, 2010], and involving workers in identifying, monitoring, and understanding exposures to risk can stimulate such an atmosphere [Clarke and Ward, 2006].

Motivations to participate: a key challenge for citizen science
To succeed, citizen science projects rely on volunteers, yet finding participants who will remain involved, especially over the long term, is a key challenge for citizen science practitioners [Crall, Kosmala et al., 2017]. As a result, several studies have examined what motivates and what hinders participation in citizen science projects.

People may be inspired by intrinsic motivations, such as fostering values that are important to them (e.g., doing something helpful for other people or the environment), increasing their own understanding (e.g., gaining new scientific knowledge), or increasing their social connections (e.g., meeting new people) [Curtis, 2018; West and Pateman, 2016]. People may also be motivated by external factors, such as a feeling that the project's goals are important, having an opportunity to help make a scientific discovery, or furthering their career [Curtis, 2018; West and Pateman, 2016]. Often, participants are already heavily interested in science or a community of interest, such as frequent users of a marine environment in a project where citizen participants collect data on marine life [Martin et al., 2016]. Projects that require more collaboration and cooperation among participants, because of the complexity of the problem they are tackling, may encourage more community development and ongoing volunteerism [Curtis, 2018].

At the same time, people are less motivated to participate in projects that are time intensive, employ technology that is difficult to use, and/or suffer from information problems (e.g., bad or missing information) [Martin et al., 2016]. Having limited resources for recruiting and retaining participants also interferes with the success of citizen science projects [Crall, Kosmala et al., 2017]. 
Another fundamental component of successful citizen science projects, particularly for sustaining participation, is communication among all project participants that is open, bidirectional, and conducted via easily accessible channels [Curtis, 2018; Jennett et al., 2016]. As a result, scholars point to the manner of how information flows in a citizen science project as an important part of its success. The idea that communication is open and bidirectional among technical and non-technical (i.e., citizen scientists) participants is also embedded in the philosophy of citizen science projects. There are levels of dialogic, or two-way, communication depending on project type [Moore et al., 2019]. As levels of engagement increase for citizen scientists (e.g., more involvement in research question development, interpretation of results) beyond just data collection, the more advanced communication needs to be.

Communication is widely recognized as a key part of successful citizen science projects. Indeed, several of the 10 guiding principles for citizen science projects defined by the European Citizen Science Association (ESCA) either directly or indirectly involve communication [Robinson et al., 2018]. For instance, the first principle states that citizen scientists should be involved in knowledge generation, a process requiring meaningful communication among technical and non-technical participants. Other principles guide practitioners to provide feedback to citizen scientists about how the data are being used and what societal or policy outcomes result from the project, as well as making the data publicly available [Robinson et al., 2018]. These principles prioritize open communication around data being collected, monitored, and evaluated in citizen science projects. Yet, despite this emphasis on the importance of communication in citizen science, little empirical research has been conducted to understand the successes or failures related to communication processes in citizen science projects [de Vries, Land-Zandstra and Smeets, 2019].

Organizations in the citizen science context
Organizations have untapped potential for addressing the challenge of how to motivate participation. They can remove some of the barriers to volunteerism. For instance, if citizen scientists are participating as part of the organization, they already have time set aside for participating in activities in that organization; therefore, they are not taking away from other personal activities, such as caretaking, household upkeep, personal hobbies, etc. - all identified as potential barriers to participation [West and Pateman, 2016]. The existing structures of an organization may allow a community of citizen scientists to be organized more easily. For example, organizations provide a way to recruit a wider range of participants, possibly through available incentives, whether they be monetary or based on recognition. Such external motivations allow for a more diverse range of participants (e.g., a wider set of perspectives beyond science enthusiasts, as well as individuals from varying socioeconomic positions) who may not already have an internal motivation encouraging them to sign up. Once participants commit to the project, the organization can help retain them by using existing communication channels. Furthermore, the organization provides access to leaders or gatekeepers who can more easily communicate with difficult-to-recruit and retain participants.

In short, organizations are an obvious setting for citizen science projects given the much needed structure they can provide for recruiting, retaining, and 
communicating with volunteer participants, the heart of any citizen science project. ${ }^{1}$ Here, we focus on citizen science projects for health-based research due to the compelling connection between organizationally based citizen science and scientific projects centered on monitoring and assessing worker health risks.

\section{The health context for organizationally based citizen science}

Recent trends in applying citizen science in health contexts have focused on monitoring exposures and behaviors relevant for health outcomes. Advances in sensor technology that allow researchers to collect a variety of health-related data at a relatively low cost have been a primary focus of health-based citizen science research [English, Richardson and Garzón-Galvis, 2018]. Such approaches not only enable researchers to tackle a bigger range and scale of scientific inquiry, but they also provide opportunities for societal advancements. For instance, a project that used a smartphone application to track air quality alongside health symptoms and behaviors during wildfire smoke exposure helped researchers develop a stronger relationship with citizens that will improve communication with them during future smoke events [Rappold et al., 2019]. Other popular applications of citizen science projects in health contexts include observational exercises in tracking self-reported behaviors using technologies such as smartphone applications, and large-scale collection of biomedical information such as DNA or microbial gut data [Wiggins and Wilbanks, 2019].

Citizen science is a novel approach for improving health and safety outcomes in workplaces. For instance, employees as citizen scientists can help monitor and collect data on risks, a significant endeavor for any single actor, such as an industrial hygienist, to undertake [Moore et al., 2019]. Furthermore, workplace safety provides a range of opportunities for projects that engage workers in both bottom-up as well as top-down approaches to citizen science [Moore et al., 2019]. In some models, citizens have as much agency as scientists in crafting scientific research questions, directing data collection, and interpreting results [Follett and Strezov, 2015]. Citizen science participants can also be involved in the scientific process in deeper ways, such as proposing research questions and studies and writing up results from the project [Crowston, Mitchell and Østerlund, 2019].

\section{Stakeholders in organizationally based citizen science}

Proposing that citizen science is appropriate for the workplace requires careful consideration of potential stakeholders and how they fit within the current definitions of those participant groups. Aspects of how we define citizen scientists include citizens as community members, holders of lay knowledge, and the identity - or, alternatively, anonymity — of participants [Eitzel et al., 2017]. In the workplace, one's employee status easily identifies someone as part of the workplace community. ${ }^{2}$ Individuals who are a part of an organization oftentimes

\footnotetext{
${ }^{1}$ While some organizations have been created to implement citizen science projects [Göbel et al., 2016], our focus is on implementing citizen science inside organizations that exist for purposes other than the development of citizen science.

${ }^{2}$ Employee status as a source of community identity may not account for the temporary workers and contractors who do not hold the same institutional knowledge and sense of belonging that come with tenure at an institution [Gossett, 2002].
} 
hold specialized knowledge from their time "on-the-ground" that they can contribute to the citizen science project. Finally, anonymizing data from participants can help address privacy concerns, but it may limit participant investment in the project and ultimately benefits received from that participation, such as efficacy or awareness. Citizen stakeholders in the workplace setting may look different from other projects, but they can still be fully engaged participants who draw upon their existing communication channels, established relationships with others in the organization, and their understanding of institutional culture in the citizen science process.

Scientists in citizen science projects are typically understood as having some formal training and employment relevant to that training (e.g., as an academic or governmental scientist) and having a goal of investigating scientific questions, sometimes with the goal of bettering some aspect of society [Eitzel et al., 2017]. In the organizational context, scientists are often external stakeholders who may partner with organization to develop an understanding of and potential responses to workplace health issues, such as risk exposures.

Other stakeholders include individuals tied explicitly to the organization itself. Examples include managers, safety officers, and industrial hygienists. These individuals would be responsible for connecting the citizen - or employee - and scientist stakeholders by facilitating communication among them. They would also help ensure that the various stakeholders are acting ethically, by, for instance, compensating employee participants. These organizationally based individuals will differ based on the institution. Furthermore, the organization itself is a stakeholder.

To define the organization as stakeholder, we can draw from community-based health research that has applied organizational approaches in a number of ways relevant for the citizen science context. One example is volunteer-based organizations that form to address a specific scientific question. For instance, SafeCast is made up solely of volunteers who came together immediately following the Fukushima disaster in 2011 to monitor radiation levels; SafeCast uses open communication among a range of citizen participants, as well as experts and officials, who are not hierarchically organized but instead networked in a "flat" structure [Brown et al., 2016]. There are also external industry- or community-based groups that work with organizations and individuals within them. For instance, health and occupational scholars have used worker advocacy centers to train leaders in low-wage and low-literacy Hispanic populations to share health and occupation knowledge in the construction industry [Forst et al., 2013]. This is an example of an organizationally based approach in a decentralized industry. Trade associations can also be effective organizations for activities common to citizen science projects, such as identifying and gathering data among a larger number of smaller institutions. For instance, a trade association of hospitals in the New York City area served as a central point of communication for gathering data from emergency department visit logs after the September $11^{\text {th }}$ terrorist attacks [Shapiro et al., 2011].

Identifying and involving stakeholders, including citizen participants, at the outset of any citizen science project and developing effective communication strategies are important parts of addressing key ethical challenges of citizen science projects 
[Skarlatidou et al., 2019]. For instance, when participants' needs, goals, and expectations are identified from the beginning, and those participants are involved in two-way communication throughout the project, they are more willing to contribute data they may deem private [Eleta et al., 2019]. Having a culture of open communication that prioritizes the values of sharing and contribution can help minimize privacy concerns [Bowser et al., 2017]. A model that involves all stakeholders in discussion of data governance increases the transparency of the process, boosts participants' willingness to contribute data, and ultimately increases the trust that project facilitators place in the quality of the data [Eleta et al., 2019]. As such, organizationally based citizen science projects face ethical challenges (e.g., privacy concerns) that any citizen science project could encounter. Organizations may be in a unique position to address some of those issues using organizational communication as a guide. In the model we propose in this paper, we highlight communicative practices within organizations that can address privacy concerns.

Next, using an input-process-output approach (see Figure 1), we review the existing body of scholarship on perspectives of culture, networks, leadership, and communication within organizations to inform the implementation of organizationally based citizen science projects.

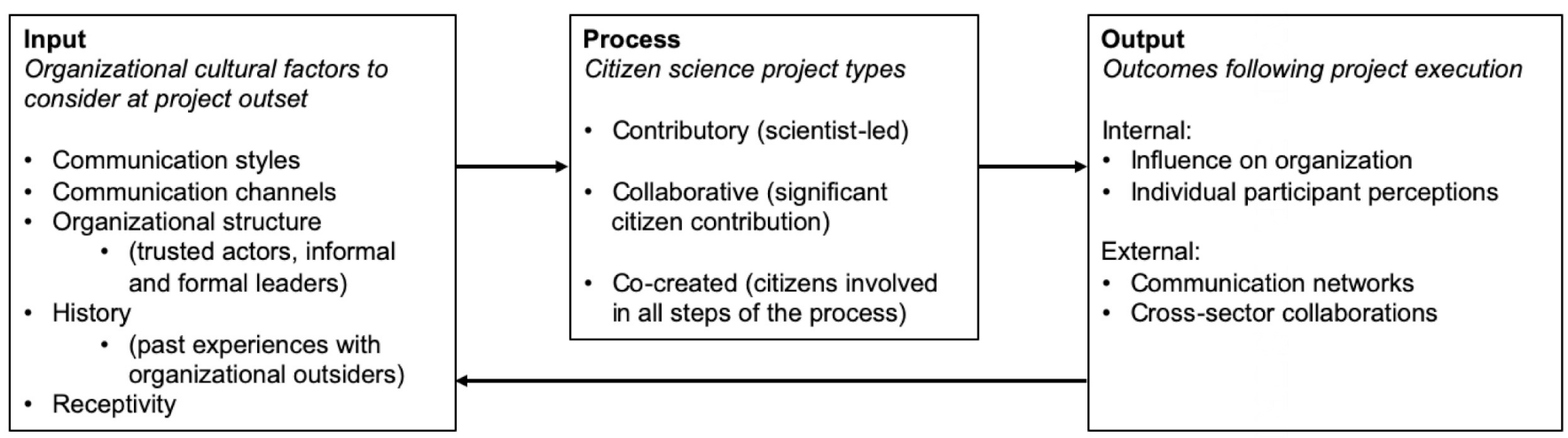

Figure 1. A model for organizationally based citizen science projects.

Input: issues to consider at the project outset
Many organizational features can inform the success of campaigns within organizations [Harrison, Morgan et al., 2011]. Our model suggests that these same factors are salient in organizationally based citizen science projects. Here, we delineate key features of organizations that can inform how citizen science projects should be implemented.

\section{Communication styles and channels}

Existing research points to the qualities of communication that best serve organizationally based citizen science projects. For instance, research on health campaigns shows that organizational structures that facilitate more frequent communication among employees positively shape their involvement with the campaign [Harrison, Morgan et al., 2011]. Information about the health campaign diffuses more quickly when there are more frequent interactions [Harrison, Morgan 
et al., 2011]. Similarly, adoption of outcomes related to community-based monitoring projects is greater among groups of individuals with high levels of frequent communication [Fernandez-Gimenez, Ballard and Sturtevant, 2008]. Therefore, organizations that foster constant dialogue will more easily adopt innovative practices that organizationally based citizen science projects may require. Frequent dialogue allows individuals in the organization to initiate a new practice like data collection while feeling free to ask about the process, quality of data, or the results.

Research has examined the effectiveness of different channels of communication in implementing campaigns. Both formal (e.g., formal memos distributed from leaders in the organization) and informal communication channels (e.g., casual chats among peers in an organization network) play a role in how knowledge is dispersed [Johnson et al., 1994]. While formal communication is important for distributing information about policies or decisions [Men, 2014], people feel more efficacious when they use informal channels and they perceive communication through those channels to be more useful for their performance in an organization [Johnson et al., 1994]. Interpersonal communication channels are particularly useful for developing technical innovations in an organization [Johnson et al., 1995] and for building community [Stein, 2006]. A formal structure for communicating about the processes of an organizationally based citizen science project can help orient individuals to the project, while more informal communication may help motivate and sustain participation in those processes.

Of course, how ideas are communicated in an organization depends upon how different individuals are positioned in the organization [Schulz, 2003]. People who are connected to more individuals, or who have centrality in an organization, are better at accurately identifying expertise in the organization [Su, 2012]. In order to exchange expertise, it helps if individuals share tasks and have access to a directory of expertise among organization members [Yuan et al., 2010]. In short, knowing where expertise lies in an organization is an important part of the production of shared knowledge within that organization.

\section{Organizational structure}

The location of trusted actors, including both formal and informal leaders is integral to the success of organizationally based citizen science projects. Where trust forms in organizations is of great scholarly and practical interest as it shapes cooperation within organizations [Kramer, 1999]. Trust that is based in emotion, or affect-based trust that is focused less on the utility of shared expertise or tasks among individuals and more on expressed relationships among those individuals, is critical for establishing cooperation in organizations [McAllister, 1995]. Individuals' communication practices - vs. their position in the organization - are critical to determining whether they are perceived as having expertise [Treem and Leonardi, 2017]. Indeed, the construct of "communicative leader" suggests that leaders in organizations should develop communication skills of open dialogue while actively pursuing feedback and use participatory decision making among various actors within the organization [Johansson, Miller and Hamrin, 2014]. Therefore, leadership often appears informally [Williams, 2015], because informal leaders are more likely than formal leaders to engage in 
interactive communication [Pielstick, 2000] and help develop group efficacy [Pescosolido, 2001]. Successful citizen science projects should locate and utilize trusted leaders who will facilitate productive communication about the processes and results of the project.

\section{Organizational history}

Past experiences within the organization likely will shape how individuals approach an implementation of citizen science. Walsh and Ungson [1991] introduced the concept of organizational memory, or the idea that organizations store information that informs current practices. Their idea that organizations contain information in different categories, or "bins," such as structures or formal roles of the organization, the organizational climate, and a culture of shared beliefs, symbols, or stories, has been influential in understanding the role of an organization's history in how it performs [Anderson and Sun, 2010]. Research shows that codification, or documentation, of information is a critical part of the development of organizational memory [Fiedler and Welpe, 2010].

Organizationally based citizen science projects should review how existing information within the organization, as well as interactions outside of the organization, have shaped current practices within the organization. These past experiences will inform how members of the organization receive a new citizen science project.

\section{Receptivity}

Receptivity addresses how open an organization is to change [Pettigrew, Woodman and Cameron, 2001]. How open employees are to change depends upon both their own orientation and on how changes are structured. For instance, an individual's level of emotional attachment and identification with an organization is related to how ready for change they are [McKay, Kuntz and Näswall, 2013]. It is not enough for an individual to hold a positive attitude toward adopting a workplace innovation; other factors (e.g., perceived social norms or perceptions of barriers) may also play a role in behavior adoption [Harrison, Muhamad et al., 2018]. Research shows that "actively involving" employees in processes of change make them more receptive to it, particularly when communication among supervisors and employees is dialogic rather than one-way [Frahm and Brown, 2007].

Further evidence suggests that communication plays an important role in an organization's receptivity to change. A communication plan is often integral to managing change in an organization. Communication plans involving mediated messages (i.e., websites or newsletters) about strategic changes and interpersonal discussions (i.e., with supervisors or peers) are instrumental in developing support for organizational changes and in how efficacious individuals feel about implementing them [Torppa and Smith, 2011]. Messages about change should address the need for it to improve the organization's performance, that it has the support of organizational leadership, and how it benefits the individuals in addition to the organization [Campbell, Carmichael and Naidoo, 2015]. Communication should be two-way and focus on relationship-building to navigate change more effectively within an organization [Ströh and Jaatinen, 2002]. 
Dialogic communication that features testimonials and personal stories is often successful in encouraging organizational change [Linke and Zerfass, 2011]. Thus, organizationally based citizen science projects, which represent a change for the organization and its employees, should foster open communication that allows for participant perspectives. When citizen science projects spend time mapping relevant stakeholders and identifying how to engage them in open communication on developing the project from the outset [Skarlatidou et al., 2019], they better ensure a positive response, even among organizations (or organizational members) typically unreceptive to change.

Process: citizen science project types
Organizationally based citizen science is based on varying types of citizen science approaches. Co-created projects are the most inclusive of citizen involvement in scientific methods, multiple stakeholders, two-way communication, and project goals that involve both society and science, while the other end of the spectrum contains contributory projects that are primarily scientist-led with minimal involvement from citizens, few stakeholder groups, one-way communication, and goals limited to the scientific realm [Moore et al., 2019]. In the middle are collaborative projects that flex among all of these factors. Collaborative projects are likely to involve citizen participation in scientific knowledge production beyond data collection and to feature communication between scientists and citizens or organizational members rather than from scientists to citizens or organizational members [Moore et al., 2019].

\section{Accounting for both inputs and processes in project implementation}

The organizational factors identified as inputs in this paper likely come into play differently with regards to the design and implementation of each project type. For example, project co-creation is more likely to result in a successful implementation of organizationally based citizen science than is a scientist-led, or top-down, project. There are, however, different means to co-creation and different levels of it. People will more willingly participate in an environment that includes their perspectives on some aspect of the scientific process: raising important questions that need to be considered, determining means for collecting data, or interpreting the results and making changes in the organization. Furthermore, while citizens can be motivated by scientific goals, which are the primary drivers of scientist-led citizen science projects, they may be more motivated to participate when the project has societal goals. Societal goals may include organizational changes (e.g., steps taken to improve air quality) or policy impacts (e.g., new regulations enacted to minimize chemical exposure). Expanding these goals beyond the scientific boundaries also widens the scope of involved stakeholders to include actors outside of the organization, such as community organizations and policy or regulatory agencies.

The model presented here fulfills a need in the literature to improve our limited understanding of the role of communication in citizen science projects de Vries, Land-Zandstra and Smeets [2019]. Here we highlight communication practices in collaborative and co-created projects that better facilitate an organizationally based citizen science project. 
- Citizen science projects that are communicated in a fashion that engages participants from the outset are likely to be more successful than those with a top-down orientation.

- Using citizen science to improve efficiencies or promote health and safety in an organization has benefits for the involved individuals, and they should be communicated.

- Citizen science projects should survey the hierarchy within the organization to understand who holds useful expertise for the project, where formal and informal leaders reside in the organization, and where communication entry points are in the existing networks of individuals.

- Citizen science approaches within organizations should engage formal and informal leaders in order to take advantage of existing nodes of expertise and relationships of trust.

- Citizen science approaches should foster frequent interactions among participants, with as much of a goal to build community as to understand risk. Forms of communication that encourage community-building (e.g., storytelling, sharing personal experiences) are particularly important in this context.

- Reviewing previous communications and experiences at an organization is integral to understanding how organizational memory might shape the design of a successful citizen science process.

Co-created and collaborative projects lend themselves to these communication practices, because they rely on the shared development of scientific questions and collaboration among various stakeholders to collect, analyze, and interpret data. Therefore, they are more likely to use existing networks and organizational memory, as well as frequent communication that highlights important points, such as benefits for individuals involved.

A co-created or collaborative project guided by the two-way communication practices described here is also better equipped to address such ethical issues as privacy of participant data. As described earlier, shared data governance models guided by communication and involvement among all stakeholders are helpful in addressing privacy concerns [Eleta et al., 2019]. These project types encourage the open communication necessary for shared decisionmaking about the management of participant data.

Output: outcomes following project execution
Organizationally based citizen science projects should explore outcomes that are internal to the organization as well as those that are external to the organization.

\section{Internal outcomes}

Communication of results. The manner in which scientific data from citizen science projects is communicated shapes attitudes about the organization. Research shows that organizations should consider employees, and particularly leaders 
among employees, as key actors in communicating about safety [Simonsson and Heide, 2018].

The citizen science model champions participation by nontraditional scientists in the process of scientific research and knowledge production, which ideally employs dialogic communication. Citizen scientists want results to be communicated to them so they know the impact of their efforts [Alender, 2016]. Research shows that formal mechanisms like websites or public lectures and workshops are used, but informal interpersonal communication was more widespread [Fernandez-Gimenez, Ballard and Sturtevant, 2008]. A mix of both channels is warranted in organizationally based citizen science. While informal channels are valuable for sharing knowledge within organizations, more formal communication of results is likely to build trust among participants. Ideally, this communication of results should also be via a "rich" channel, such as a face-to-face interaction, and be available to participants in a variety of ways to increase their likelihood of understanding [Purvis et al., 2017].

Communication strategies should also involve all stakeholders, such as an advisory board, that can help identify the information needs of the audience for communication of results [Ferris and Sass-Kortsak, 2011]. Another best practice for communication of research results is to identify a trained delegate knowledgeable about both the study and the community of participants to communicate the results and be available to answer follow-up questions [Hintz and Dean, 2019]. Organizational leaders can help identify such an individual or group of individuals.

Influence on organizations. Alliances or partnerships are frequently established to organize community-based projects, which often results in greater trust and credibility among various stakeholders, as well as a greater sense of community among participants [Fernandez-Gimenez, Ballard and Sturtevant, 2008]. Therefore, citizen science projects may be sustained in organizations due to the already established trust and community among its members.

Individual participant outcomes. Research on citizen science projects suggests they can shape different outcomes for participants. Some literature shows that involvement influences awareness, knowledge, or interest in science, as well as behaviors, but not attitudes [Bonney et al., 2009; Brossard, Lewenstein and Bonney, 2005]. Other research shows that participation in citizen science projects can shape attitudes and knowledge, as well as behavior [Crall, Jordan et al., 2013]. Additional research suggests that participants gain knowledge about topics in the project and citizen science itself, but not as much knowledge about the scientific process [Land-Zandstra et al., 2016]. In short, people who get involved in citizen science projects are affected. However, research has yet to examine what people learn or think about beyond the scientific topics or processes that are the focus of the project. This is an important area of research for fully understanding the implications of implementing citizen science in organizations. For instance, how does a citizen science project shape views of the organization itself? Do employees feel more efficacious about the topic under scrutiny in the project? Do they learn more about the organization's processes and culture? Do they have different attitudes about those processes? Is a citizen science approach effective in helping 
the organization attain its intended goals? All of these outcomes are likely, yet the organizational perspective of citizen science outcomes has yet to be fully explored.

\section{External outcomes}

The question remains as to whether citizen science approaches can be sustained longer than the completion of a single project. Can they, for example, be sustained long enough to effect change across an industry or sector? Understanding where power and hierarchies lie in an interorganizational network is a key part of understanding how communication flows between organizations and sustains relationships among those organizations [Doerfel, 2015]. For instance, a network that is highly centralized with a few key actors has few gatekeepers who manage the information exchanged in the network, while a densely connected and decentralized network is more likely to have a number of actors who distribute information [Doerfel, 2015]. When collaborations across organizations occur, leaders in each organization must coordinate with each other for sustained success [Williams, 2015].

Once a citizen science approach has been successfully implemented within an organization, sustaining and distributing it across an industry requires identifying connecting nodes in the communication networks that will serve as intermediaries in the exchange of information. Such intermediaries may include industry associations, trade publications, or partnerships among communities and academic organizations [Ramirez-Andreotta et al., 2015; Reges et al., 2016; van Vliet, Bron and Mulder, 2014]. These key actors can assist with recruiting participants and communicating findings of individual projects to the industry.

To understand how citizen science practices might diffuse across a sector, it is important to understand the role of communication among these sector leaders. Yet, thus far, citizen science literature has not explored the role of communication in this larger sense. In citizen science projects, communication is primarily viewed as a tool for reaching participants (e.g., internet and social media) and for involving them in practices like data collection or monitoring (e.g., mobile devices and distributed sensor networks). For instance, digital technologies like smartphones are used for recruiting participants, managing the collection of data, and communicating among citizen participants and researchers [Crain, Cooper and Dickinson, 2014; Newman et al., 2012]. A key question remains: How do researchers map the information exchanged during citizen science projects onto the existing networks of communication within and across organizations?

In summary, internal goals for successful organizationally based citizen science include using processes that increase trust, foster learning and interest in science, responsibly communicate findings, and address problems that arise. External goals may include adopting a systems approach among organizations by locating central nodes, or leaders, that are likely to facilitate regular, interactive communication to enact industry-wide change.

While the model proposed in this paper focuses primarily on factors related to communication to sustain citizen science approaches within organizations and across industries, there are certainly other important factors. For instance, external 
impacts of participatory science approaches in organizations and across sectors could influence worker safety policies or shifts in regulatory processes [Corburn, 2007]. Implementing policies requires collaborative and dialogic communication that allows for shared knowledge among all individuals [LeGreco and Canary, 2011]. Additionally, the impact organizationally based citizen science projects have on an organization's clients or customers is likely to shape how other organizations in that industry engage in the approaches. Finally, an organization's goals, including profitability, certainly impact decision making. Here, we can turn to the example of health and safety monitoring of workers as a goal that ideally would supersede a profitability motive, but the two are also likely intertwined. Gaining an understanding of the organization's culture, values, and norms at the outset can help address potential clashes between the organization's goals and the project's goals.

\section{Conclusion}

Organizations provide structures for implementing citizen science projects. Here, we suggest health and safety in the workplace as a context for organizationally based citizen science. To implement a successful organizationally based citizen science project, we must consider the culture, history, and communication styles within an organization. These organizational characteristics also shape how sustainable a citizen science project will be within the organization and across a sector. The model presented here highlights the important considerations for the inputs, processes, and outcomes of organizationally based citizen science.

Acknowledgments

Information provided in this publication was supported by National Institute for Occupational Safety and Health of the Centers for Disease Control under award numbers R01OH011660 and 16IPA1616814.

\section{References}

Alender, B. (2016). 'Understanding volunteer motivations to participate in citizen science projects: a deeper look at water quality monitoring'. JCOM 15 (03), A04. https://doi.org/10.22323/2.15030204.

Anderson, M. H. and Sun, P. Y. T. (2010). 'What have scholars retrieved from Walsh and Ungson (1991)? A citation context study'. Management Learning 41 (2), pp. 131-145. https://doi.org/10.1177/1350507609341091.

Bonney, R., Cooper, C. B., Dickinson, J., Kelling, S., Phillips, T., Rosenberg, K. V. and Shirk, J. (2009). 'Citizen Science: a Developing Tool for Expanding Science Knowledge and Scientific Literacy'. BioScience 59 (11), pp. 977-984. https://doi.org/10.1525/bio.2009.59.11.9.

Bowser, A., Shilton, K., Preece, J. and Warrick, E. (2017). 'Accounting for privacy in citizen science: ethical research in a context of openness'. In: Proceedings of the 2017 ACM Conference on Computer Supported Cooperative Work and Social Computing - CSCW'17. New York, NY, U.S.A.: ACM Press, pp. 2124-2136. https://doi.org/10.1145/2998181.2998305.

Brossard, D., Lewenstein, B. and Bonney, R. (2005). 'Scientific knowledge and attitude change: The impact of a citizen science project'. International Journal of Science Education 27 (9), pp. 1099-1121. https://doi.org/10.1080/09500690500069483. 
Brown, A., Franken, P., Bonner, S., Dolezal, N. and Moross, J. (2016). 'Safecast: successful citizen-science for radiation measurement and communication after Fukushima'. Journal of Radiological Protection 36 (2), S82-S101. https://doi.org/10.1088/0952-4746/36/2/s82.

Campbell, K. S., Carmichael, P. and Naidoo, J. S. (2015). 'Responding to hostility: evidence-based guidance for communication during planned organizational change'. Business and Professional Communication Quarterly 78 (2), pp. 197-214. https://doi.org/10.1177/2329490614551570.

Clarke, S. and Ward, K. (2006). 'The role of leader influence tactics and safety climate in engaging employees' safety participation'. Risk Analysis 26 (5), pp. 1175-1185. https://doi .org/10.1111/j.1539-6924.2006.00824.x.

Corburn, J. (2007). 'Community knowledge in environmental health science: co-producing policy expertise'. Environmental Science \& Policy 10 (2), pp. 150-161. https://doi.org/10.1016/j.envsci.2006.09.004.

Crain, R., Cooper, C. and Dickinson, J. L. (2014). 'Citizen science: a tool for integrating studies of human and natural systems'. Annual Review of Environment and Resources 39 (1), pp. 641-665. https://doi.org/10.1146/annurev-environ-030713-154609.

Crall, A. W., Jordan, R., Holfelder, K., Newman, G. J., Graham, J. and Waller, D. M. (2013). 'The impacts of an invasive species citizen science training program on participant attitudes, behavior, and science literacy'. Public Understanding of Science 22 (6), pp. 745-764. https: //doi.org/10.1177/0963662511434894. PMID: 23825234.

Crall, A. W., Kosmala, M., Cheng, R., Brier, J., Cavalier, D., Henderson, S. and Richardson, A. (2017). 'Volunteer recruitment and retention in online citizen science projects using marketing strategies: lessons from Season Spotter'. JCOM 16 (01), A1. URL: https://jcom.sissa.it/archive/16/01/JCOM_1601_2017_A01.

Crowston, K., Mitchell, E. and Østerlund, C. (2019). 'Coordinating advanced crowd work: extending citizen science'. Citizen Science: Theory and Practice 4 (1), p. 16. https://doi.org/10.5334/cstp.166.

Curtis, V. (2018). Online citizen science and the widening of academia: distributed engagement with research and knowledge production. New York, NY, U.S.A.: Springer Science+Business Media. https://doi.org/10.1007/978-3-319-77664-4.

de Vries, M., Land-Zandstra, A. and Smeets, I. (2019). 'Citizen scientists' preferences for communication of scientific output: a literature review'. Citizen Science: Theory and Practice 4 (1), p. 2. https://doi .org/10.5334/cstp. 136.

Doerfel, M. L. (2015). 'Networked forms of organizing, disaster-related disruptions and public health'. In: Organizations, communication and health. New York, NY, U.S.A.: Routledge, pp. 365-383. https://doi.org/10.4324/9781315723020-22.

Eitzel, M. V., Cappadonna, J. L., Santos-Lang, C., Duerr, R. E., Virapongse, A., West, S. E., Kyba, C. C. M., Bowser, A., Cooper, C. B., Sforzi, A., Metcalfe, A. N., Harris, E. S., Thiel, M., Haklay, M., Ponciano, L., Roche, J., Ceccaroni, L., Shilling, F. M., Dörler, D., Heigl, F., Kiessling, T., Davis, B. Y. and Jiang, Q. (2017). 'Citizen science terminology matters: exploring key terms'. Citizen Science: Theory and Practice 2 (1), p. 1. https://doi .org/10.5334/cstp. 96.

Eleta, I., Clavell, G. G., Righi, V. and Balestrini, M. (2019). 'The promise of participation and decision-making power in citizen science'. Citizen Science: Theory and Practice 4 (1). https : / /doi .org/10.5334/cstp.171. 
English, P. B., Richardson, M. J. and Garzón-Galvis, C. (2018). 'From crowdsourcing to extreme citizen science: participatory research for environmental health'. Annual Review of Public Health 39 (1), pp. 335-350. https://doi.org/10.1146/annurev-publhealth-040617-013702.

Fernandez-Gimenez, M. E., Ballard, H. L. and Sturtevant, V. E. (2008). 'Adaptive Management and Social Learning in Collaborative and Community-Based Monitoring: a Study of Five Community-Based Forestry Organizations in the western USA'. Ecology and Society 13 (2), p. 4. https://doi.org/10.5751/es-02400-130204.

Ferris, L. and Sass-Kortsak, A. (2011). 'Sharing research findings with research participants and communities'. International Journal of Occupational and Environmental Medicine 2 (3), pp. 172-181.

URL: https://www . theijoem.com/ijoem/index.php/ijoem/article/view/99.

Fiedler, M. and Welpe, I. (2010). 'How do organizations remember? The influence of organizational structure on organizational memory'. Organization Studies 31 (4), pp. 381-407. https://doi.org/10.1177/0170840609347052.

Follett, R. and Strezov, V. (2015). 'An analysis of citizen science based research: usage and publication patterns'. PLOS ONE 10 (11), e0143687. https://doi.org/10.1371/journal.pone.0143687.

Forst, L., Ahonen, E., Zanoni, J., Holloway-Beth, A., Oschner, M., Kimmel, L., Martino, C., Rodriguez, E., Kader, A., Ringholm, E. and Sokas, R. (2013). 'More than training: community-based participatory research to reduce injuries among hispanic construction workers'. American Journal of Industrial Medicine 56 (8), pp. 827-837. https://doi.org/10.1002/ajim. 22187.

Frahm, J. and Brown, K. (2007). 'First steps: linking change communication to change receptivity'. Journal of Organizational Change Management 20 (3), pp. 370-387. https://doi.org/10.1108/09534810710740191.

Göbel, C., Cappadonna, J., Newman, G., Zhang, J. and Vohland, K. (2016). 'More than just networking for citizen science. Examining core roles of practitioner organizations'. In: Analyzing the role of citizen science in modern research. Ed. by L. Ceccaroni and J. Piera. U.S.A.: IGI global. https://doi.org/10.4018/978-1-5225-0962-2.ch002.

Gossett, L. (2002). 'Kept at arm's length: questioning the organizational desirability of member identification'. Communication Monographs 69 (4), pp. 385-404. https://doi.org/10.1080/03637750216548.

Harrison, T. R., Morgan, S. E., Chewning, L. V., Williams, E. A., Barbour, J. B., Di Corcia, M. J. and Davis, L. A. (2011). 'Revisiting the worksite in worksite health campaigns: evidence from a multisite organ donation campaign'. Journal of Communication 61 (3), pp. 535-555. https://doi.org/10.1111/j.1460-2466.2011.01553.x.

Harrison, T. R., Muhamad, J. W., Yang, F., Morgan, S. E., Talavera, E., Caban-Martinez, A. and Kobetz, E. (2018). 'Firefighter attitudes, norms, beliefs, barriers and behaviors toward post-fire decontamination processes in an era of increased cancer risk'. Journal of Occupational and Environmental Hygiene 15 (4), pp. 279-284. https://doi.org/10.1080/15459624.2017.1416389.

Hintz, E. A. and Dean, M. (2019). 'Best practices for returning research findings to participants: methodological and ethical considerations for communication researchers'. Communication Methods and Measures 14 (1), pp. 38-54. https://doi.org/10.1080/19312458.2019.1650165. 
Jennett, C., Kloetzer, L., Schneider, D., Iacovides, I., Cox, A., Gold, M., Fuchs, B., Eveleigh, A., Mathieu, K., Ajani, Z. and Talsi, Y. (2016). 'Motivations, learning and creativity in online citizen science'. JCOM 15 (03), A05.

https://doi.org/10.22323/2.15030205.

Johansson, C., Miller, V. D. and Hamrin, S. (2014). 'Conceptualizing communicative leadership: a framework for analysing and developing leaders' communication competence'. Corporate communications: an international journal 19 (2), pp. 147-165. https://doi.org/10.1108/ccij-02-2013-0007.

Johnson, J. D., Donohue, W. A., Atkin, C. K. and Johnson, S. (1994). 'Differences between formal and informal communication channels'. Journal of Business Communication 31 (2), pp. 111-122. https://doi.org/10.1177/002194369403100202.

- (1995). 'Differences between organizational and communication factors related to contrasting innovations'. Journal of Business Communication 32 (1), pp. 65-80. https://doi.org/10.1177/002194369503200104.

Kramer, R. M. (1999). 'Trust and distrust in organizations: emerging perspectives, enduring questions'. Annual Review of Psychology 50 (1), pp. 569-598. https://doi.org/10.1146/annurev.psych.50.1.569.

Land-Zandstra, A. M., Devilee, J. L. A., Snik, F., Buurmeijer, F. and van den Broek, J. M. (2016). 'Citizen science on a smartphone: Participants' motivations and learning'. Public Understanding of Science 25 (1), pp. 45-60. https://doi.org/10.1177/0963662515602406.

LeGreco, M. and Canary, H. E. (2011). 'Enacting sustainable school-based health initiatives: a communication-centered approach to policy and practice'. American Journal of Public Health 101 (3), pp. 431-437. https://doi.org/10.2105/ajph.2009.186858.

Linke, A. and Zerfass, A. (2011). 'Internal communication and innovation culture: developing a change framework'. Journal of Communication Management 15 (4), pp. 332-348. https://doi.org/10.1108/13632541111183361.

Martin, V., Christidis, L., Lloyd, D. and Pecl, G. (2016). 'Understanding drivers, barriers and information sources for public participation in marine citizen science'. JCOM 15 (02), A02. https : //doi .org/10.22323/2.15020202.

McAllister, D. J. (1995). 'Affect- and cognition-based trust as foundations for interpersonal cooperation in organizations'. Academy of Management Journal 38 (1), pp. 24-59. https://doi.org/10.2307/256727.

McKay, K., Kuntz, J. R. C. and Näswall, K. (2013). 'The effect of affective commitment, communication and participation on resistance to change: the role of change readiness'. New Zealand Journal of Psychology 42 (1), pp. 29-40.

Men, L. R. (2014). 'Strategic internal communication: transformational leadership, communication channels and employee satisfaction'. Management Communication Quarterly 28 (2), pp. 264-284. https://doi.org/10.1177/0893318914524536.

Moore, A. C., Anderson, A. A., Long, M., McKernan, L. T. and Volckens, J. (2019). 'The power of the crowd: prospects and pitfalls for citizen science in occupational health'. Journal of Occupational and Environmental Hygiene 16 (3), pp. 191-198. https://doi.org/10.1080/15459624.2019.1566733.

Newman, G., Wiggins, A., Crall, A., Graham, E., Newman, S. and Crowston, K. (2012). 'The future of citizen science: emerging technologies and shifting paradigms'. Frontiers in Ecology and the Environment 10 (6), pp. 298-304. https://doi.org/10.1890/110294. 
Pescosolido, A. T. (2001). 'Informal leaders and the development of group efficacy'. Small Group Research 32 (1), pp. 74-93.

https://doi.org/10.1177/104649640103200104.

Pettigrew, A. M., Woodman, R. W. and Cameron, K. S. (2001). 'Studying organizational change and development: challenges for future research'. Academy of Management Journal 44 (4), pp. 697-713. https://doi.org/10.2307/3069411.

Pielstick, C. D. (2000). 'Formal vs. informal leading: a comparative analysis'. Journal of Leadership Studies 7 (3), pp. 99-114. https://doi.org/10.1177/107179190000700307.

Purvis, R. S., Abraham, T. H., Long, C. R., Stewart, M. K., Warmack, T. S. and McElfish, P. A. (2017). 'Qualitative study of participants' perceptions and preferences regarding research dissemination'. AJOB Empirical Bioethics 8 (2), pp.69-74. https://doi.org/10.1080/23294515.2017.1310146.

Ramirez-Andreotta, M. D., Brusseau, M. L., Artiola, J., Maier, R. M. and Gandolfi, A. J. (2015). 'Building a co-created citizen science program with gardeners neighboring a superfund site: the Gardenroots case study'. International Public Health Journal 7 (1), p. 18.

Rappold, A. G., Hano, M. C., Prince, S., Wei, L., Huang, S. M., Baghdikian, C., Stearns, B., Gao, X., Hoshiko, S., Cascio, W. E., Diaz-Sanchez, D. and Hubbell, B. (2019). 'Smoke sense initiative leverages citizen science to address the growing wildfire-related public health problem'. GeoHealth 3 (12), pp. 443-457. https://doi.org/10.1029/2019gh000199.

Reges, H. W., Doesken, N., Turner, J., Newman, N., Bergantino, A. and Schwalbe, Z. (2016). 'CoCoRaHS: the evolution and accomplishments of a volunteer rain gauge network'. Bulletin of the American Meteorological Society 97 (10), pp. 1831-1846. https://doi.org/10.1175/bams-d-14-00213.1.

Robinson, L. D., Cawthray, J. L., West, S. E., Bonn, A. and Ansine, J. (2018). 'Ten principles of citizen science'. In: Citizen science: innovation in open science, society and policy. Ed. by S. Hecker, M. Haklay, A. Bowser, Z. Makuch, J. Vogel and A. Bonn. London, U.K.: UCL Press, pp. 1-23. https://doi.org/10.14324/111.9781787352339.

Rowbotham, S., McKinnon, M., Leach, J., Lamberts, R. and Hawe, P. (2019). 'Does citizen science have the capacity to transform population health science?' Critical Public Health 29 (1), pp. 118-128. https://doi.org/10.1080/09581596.2017.1395393.

Schulz, M. (2003). 'Pathways of relevance: exploring inflows of knowledge into subunits of multinational corporations'. Organization Science 14 (4), pp. 440-459. https://doi.org/10.1287/orsc.14.4.440.17483.

Shapiro, J. S., Mostashari, F., Hripcsak, G., Soulakis, N. and Kuperman, G. (2011). 'Using health information exchange to improve public health'. American Journal of Public Health 101 (4), pp. 616-623. https://doi.org/10.2105/ajph.2008.158980.

Simonsson, C. and Heide, M. (2018). 'How focusing positively on errors can help organizations become more communicative: an alternative approach to crisis communication'. Journal of Communication Management 22 (2), pp. 179-196. https://doi.org/10.1108/jcom-04-2017-0044. 
Skarlatidou, A., Suskevics, M., Göbel, C., Prūse, B., Tauginiené, L., Mascarenhas, A., Mazzonetto, M., Sheppard, A., Barrett, J., Haklay, M., Baruch, A.,

Moraitopoulou, E.-A., Austen, K., Baïz, I., Berditchevskaia, A., Berényi, E., Hoyte, S., Kleijssen, L., Kragh, G., Legris, M., Mansilla-Sanchez, A., Nold, C., Vitos, M. and Wyszomirski, P. (2019). 'The value of stakeholder mapping to enhance co-creation in citizen science initiatives'. Citizen Science: Theory and Practice 4 (1), p. 24. https://doi .org/10.5334/cstp. 226.

Stein, A. (2006). 'Employee communications and community: an exploratory study'. Journal of Public Relations Research 18 (3), pp. 249-264. https://doi.org/10.1207/s1532754xjprr1803_3.

Ströh, U. and Jaatinen, M. (2002). 'New approaches to communication management for transformation and change in organisations'. Journal of Communication Management 6 (2), pp. 148-165. https: //doi.org/10.1108/13632540210807008.

$\mathrm{Su}, \mathrm{C}$. (2012). 'Who knows who knows what in the group? The effects of communication network centralities, use of digital knowledge repositories and work remoteness on organizational members' accuracy in expertise recognition'. Communication Research 39 (5), pp. 614-640. https://doi.org/10.1177/0093650211433825.

Torppa, C. B. and Smith, K. L. (2011). 'Organizational change management: a test of the effectiveness of a communication plan'. Communication Research Reports 28 (1), pp. 62-73. https://doi.org/10.1080/08824096.2011.541364.

Treem, J. W. and Leonardi, P. M. (2017). 'Recognizing expertise: factors promoting congruity between individuals' perceptions of their own expertise and the perceptions of their coworkers'. Communication Research 44 (2), pp. 198-224. https://doi.org/10.1177/0093650215605154.

van Vliet, A. J. H., Bron, W. A. and Mulder, S. (2014). 'The how and why of societal publications for citizen science projects and scientists'. International Journal of Biometeorology 58 (4), pp. 565-577. https://doi.org/10.1007/s00484-014-0821-9.

Walsh, J. P. and Ungson, G. R. (1991). 'Organizational memory'. Academy of Management Review 16 (1), pp. 57-91. https://doi.org/10.5465/amr.1991.4278992.

West, S. and Pateman, R. (2016). 'Recruiting and Retaining Participants in Citizen Science: What Can Be Learned from the Volunteering Literature?' Citizen Science: Theory and Practice 1 (2), p. 15. https://doi.org/10.5334/cstp.8.

Wiggins, A. and Wilbanks, J. (2019). 'The rise of citizen science in health and biomedical research'. The American Journal of Bioethics 19 (8), pp. 3-14. https://doi.org/10.1080/15265161.2019.1619859.

Williams, E. A. (2015). 'Leading interorganizational health collaborations: the importance of multi-dyadic relationships'. In: Organizations, communication and health. New York, NY, U.S.A.: Routledge, pp. 330-346. https://doi.org/10.4324/9781315723020-20.

Yuan, Y. C., Fulk, J., Monge, P. R. and Contractor, N. (2010). 'Expertise directory development, shared task interdependence and strength of communication network ties as multilevel predictors of expertise exchange in transactive memory work groups'. Communication Research 37 (1), pp. 20-47. https://doi.org/10.1177/0093650209351469.

Zohar, D. (2010). 'Thirty years of safety climate research: reflections and future directions'. Accident Analysis \& Prevention 42 (5), pp. 1517-1522. https://doi.org/10.1016/j.aap.2009.12.019. 
Ashley Anderson is an associate professor in the Department of Journalism and Media Communication at Colorado State University. Her research interests include public opinion and public engagement around issues of science and emerging technology, particularly in the digital media environment.

E-mail: Ashley.A.Anderson@colostate.edu.

Elizabeth A. Williams is an Associate Professor of Organizational and Health Communication at Colorado State University. Her current research focuses on the practices and processes that high reliability organizations (e.g., fire departments) employ to ensure the health and safety of their members.

E-mail: elizabeth.a.williams@colostate.edu.

Marilee Long (PhD, University of Wisconsin-Madison) is a professor in the Department of Journalism and Media Communication at Colorado State University. In her current research, she studies the effects of citizen-science approaches on people's health attitudes and behaviors. E-mail: marilee.long@colostate.edu.

Ellison Carter is an environmental engineer, and her current research combines interests and expertise in indoor and outdoor air quality, exposure science, and chemistry. She aims to answer questions relevant to energy, environmental health, and housing policy. She is working to understand patterns and predictors of variability in environmental exposures. E-mail: ellison.carter@colostate.edu.

John Volckens is a professor of mechanical engineering at Colorado State University with affiliate appointments in biomedical engineering and occupational/environmental health. He studies air pollution emissions, exposures, and health effects. E-mail: john.volckens@colostate.edu.

\section{How to cite}

Anderson, A. A., Williams, E. A., Long, M., Carter, E. and Volckens, J. (2020). 'Organizationally based citizen science: considerations for implementation'. JCOM 19 (03), A01. https:/ /doi.org/10.22323/2.19030201. 